\title{
Technical Dimensions of the Development of Unmanned Aerial Systems and Their Impact on Public Service Uses
}

\author{
András NÉMETH ${ }^{1}$
}

\begin{abstract}
Due to the processes and specialized research of the revolution in technological and scientific information of the last few decades, the development of Unmanned Aircraft Systems (UAS) has now reached the state where it may become a defining factor in the market of civil technologies. In the wake of efforts to enhance aviation safety since the first generation of multicopters, hobby and professional tools have become available that-provided that statutory requirements are flexible enough-could be used in corporate and government sectors alike.

However, the use of such equipment to improve public services would require a strategic-level policy change. Due to rapid technological changes, the speed at which drones are developing is unprecedented, and such equipment is becoming dated significantly faster than, for example, the planned life-cycle of military equipment. These circumstances call for a solution that breaks away from existing procurement principles, and is able to continuously provide government organizations with equipment that meets the latest technical standards, and supports the efficient execution of the most diverse specialized tasks.

This publication aims to present the complexity, technical dimensions and development trends of "drone science", along with suggestions on how their use could be efficiently integrated into the toolbox of public service tasks.
\end{abstract}

Keywords: Unmanned Aircraft Systems, drones, system of public-service tasks, development trends

\section{Introduction}

The term "global drone market" has only emerged in the last five years, and the related market research and preparation of various forecasts has already grown into an independent business segment. This fact alone shows that the use of unmanned aerial vehicles (UAVs) and the associated technology is skyrocketing, bringing about a potentially significant change in many areas within only a few years. Since the emergence of the first similar forecasts, all analyses show a dynamic expansion of this market segment, propelled both by Unmanned Aircraft Systems, and by activities related to civil purpose equipment (e.g. design and manufacture of components and equipment, system integration, sensor systems, data processing solutions and insurance). Some variations do exist between individual

Ph.D., National University of Public Service, Faculty of Military Sciences and Officer Training, Department of Electronic Warfare; e-mail: nemeth.andras@uni-nke.hu

The research has been supported by the ÚNKP-17-4-3-NKE-71, the New National Excellence Program of the Ministry of Human Capacities. 
forecasts - in terms of the extent and rate of extension-however, they all agree that the time of the forecasted breakthrough is still uncertain. This is basically caused by sluggish attempts to adapt to statutory requirements. Taking a closer look at the data of a much-referenced analysis published in June 2016 (Fig. 1), [1] it becomes clear that for at least the forthcoming years, the hegemony of military expenses remains unchallenged. At the same time, attention may be drawn to the fact that the 9 percent of the entire market spent on civil uses (mostly by the government) in 2016 is forecasted to double to 18 percent within five years (by 2021). For the market of civil uses this means USD 1.8 billion globally, which translates to a 2.25 -fold increase. For 2024 this amount—primarily due to the intense expansion of public service and corporate uses - will increase to a 3.3-billion-dollar scale, almost doubling in three years. It will cover slightly more than one quarter of the entire market, exceeding 12 billion dollars. While the entire market will expand by 70 percent in eight years, due to the dynamic growth of the civil—mostly government—use, this segment will show a result of more than 400 percent.

\section{Global Aerial Drone Market}

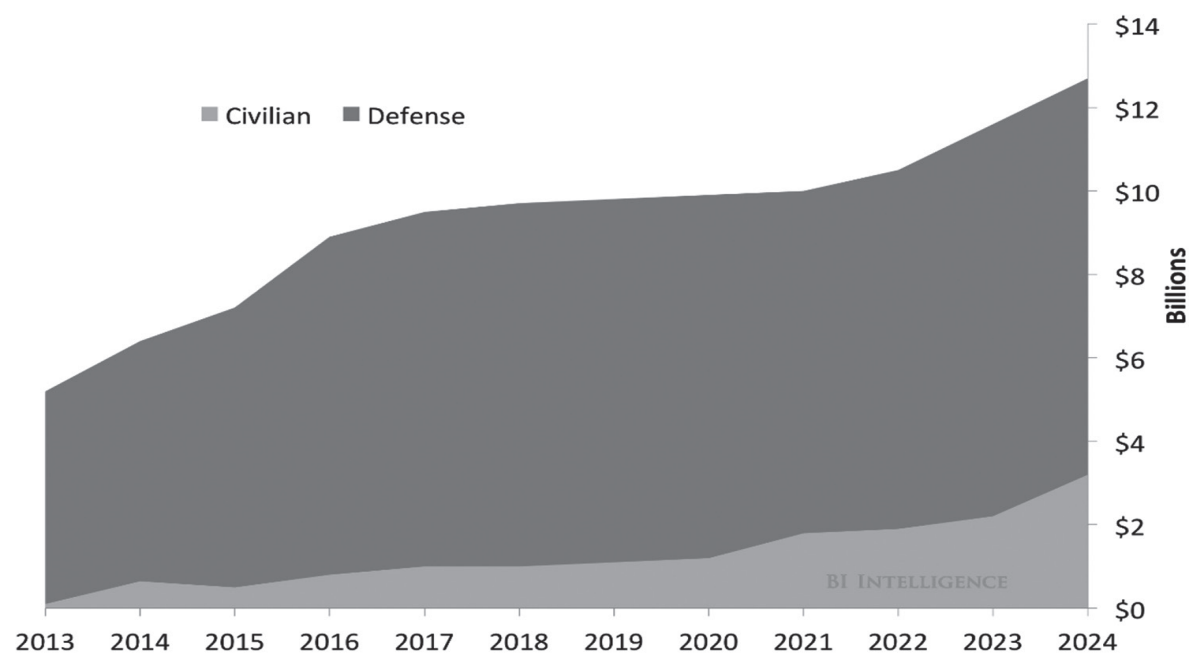

Figure 1. Global Aerial Drone Market. [2]

The results of a significantly later study were published in 2018. Though the methodology shows significant variations, it is still obvious that analysts are expecting a turnover of more than 20 billion dollars for this year, which — if the average annual growth rate (CAGR) exceeds 14 percent-will exceed 52 billion dollars by 2025. For this year they primarily expect a growth in the fixed-wing UAV market as opposed to the multicopter market, as the former possess better parameters in terms of military, public service and commercial/ delivery use (flight time, payload, etc.). Based on this, the largest segment will be covered by the medium- and high-altitude and medium- and long-range UAVs' turnover, dominated by North American companies (45 percent). The European share will be low by all calculation criteria (20 percent), which is partly explained by the lack of unified European legislation on the matter. Considering this, the list of the top players, General Atomics (USA), Northrop 
Grumman (USA), Textron (USA), Boeing (USA), DJI (China), Parrot (France), 3D Robotics (USA) and Aeryon Labs (Canada) is no surprise. [3]

To fulfil these long-term forecasts, legislation attempts aiming to simplify the use of UAV systems (mainly in Europe), and the technological developments allowing for a large-scale and safe airspace use, will need to be promptly realized.

The primary goal of this publication is to provide an overview of the underlying linkages of the scientific and technological developments and their impacts and expected results, while integrating those in attempts to improve the efficiency of the public service task system.

\section{Drones and Science}

The terminology used for unmanned, remotely operated aircraft has changed several times in the last decades. Today, official documents issued by international professional organizations belong to one of two main schools: the International Civil Aviation Organization (ICAO) opted for Remotely Piloted Aircraft System (RPAS), also used by EUROCONTROL, the European Aviation Safety Agency (EASA) and several national aviation organizations. As opposed to this, the Federal Aviation Administration (FAA) and the British Civil Aviation Authority (CAA) uses the term Unmanned Aerial/Aircraft System (UAS). The most important connection between the two terms is the approach to perceive such aircraft as a system. The term "drone" is used in French-speaking territories; thus, this is the term preferred by the French Civil Aviation Administration (DGCA) in its communications. It is also the term used by civil and recreational users, along with the media. [4] [5] In this publication, the terms UAS, UAV and drone are used in a quasi-interchangeable manner, as synonyms of the official "unmanned aerial vehicle" preferred by operational Hungarian legislation.

Back to the system approach, despite several sensor systems and other components essential for the operation of the vehicle, the UAV is regarded only as a subsystem (aerial subsystem), for the operation of which, amongst other things, a ground-based subsystem is essential, with the functions of remote control and a communication subsystem enabling data transfer between the two. Expanding the definition even further, the human resources necessary for the operation can also be regarded as a subsystem (operators), even so the procedures associated with the safe operation of the system (e.g. checks, inspections and maintenance).

In order to understand the importance of handling Unmanned Aircraft Systems as a strategic industry by government players - as the largest prospective drone users - it is worth identifying the disciplines in the Hungarian Academy of Sciences (MTA) ${ }^{2}$ nomenclature [6] that are directly or indirectly used or affected by this dynamically growing market segment.

The relation system between science and Unmanned Aircraft Systems is more complex than it seems at first glance. At first, the development of natural non-life sciences, mathematics and technology-enabled creation of the systems we know as UAV today, appeared. At the same time, the rapid emergence and widespread use of such equipment also had an impact on life sciences, humanities, and social sciences. In the future, it will bring about changes in the very basics of many disciplines and their approaches. Through agricultural applications-based on the discipline nomenclature - the most affected life sciences are some areas of agrarian sciences,

2 Magyar Tudományos Akadémia - the Hungarian Academy of Sciences. 
A. NÉMETH: Technical Dimensions of the Development of Unmanned Aerial Systems...

while within humanities and social sciences it would be archaeology, law, economic sciences, war sciences, and regional sciences that are increasingly affected. These are the sciences that, amongst other things, discuss the government task systems falling directly or indirectly under the umbrella term of public services. Figure 2 shows the system of non-life sciences that can be associated with UASs, based on the MTA's nomenclature.

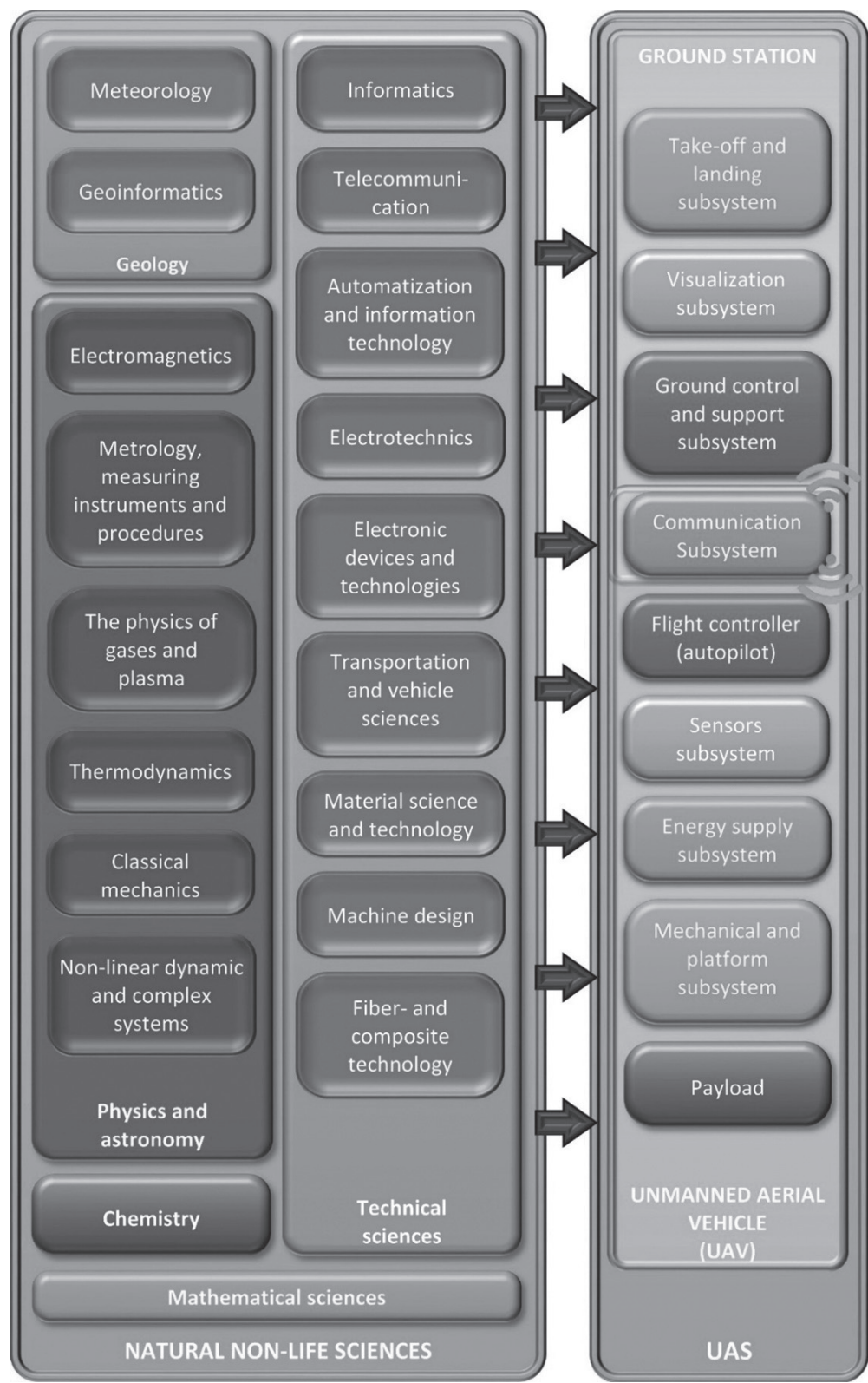

Figure 2. The Relation of Science and UAS.

[Created by the author.] 
If aviation itself is our starting point, we have to start our study in the field of physics and astronomy. An important segment of classical mechanics is fluid mechanics and gas dynamics, which are essential to modelling the motion of heavier-than-air objects in the air, and to the design and construction of aircraft. Examining the stability, the forces or the physics of changing the direction of movement of aircraft would require us to use Newton's mechanics, the physics of solid objects, hydraulics, or applied mechanics. If we handle all UAV subsystems as a complex entity, we deal with thermodynamics, the physics of gases and plasma, non-linear dynamic and complex systems, or even electromagnetics. This latter is the basics of radio frequency-based remote control and wireless communication. The knowledge of several fields of chemistry is necessary to design and manufacture energy sources generating energy from chemical transformations (for example batteries), and to examine their features. Mathematical sciences establish the framework of natural sciences' activities, and provide them with a calculation tool system, while any other academic field and discipline also uses several achievements of mathematics. The connection of geology and drones is not only a broad, indirect connection: geoinformatics provide the theoretical background of the functions of air navigation, flight planning and independent flight. For several applications, the achievements of this discipline are used for evaluation and digital map imaging of the results. Similarly, meteorology directly affects flight safety, which can be enhanced with aviation meteorology research.

At the same time the design, functional modelling, simulation, manufacturing, testing or compliance verification of Unmanned Aircraft Systems or their subsystems, components or parts, primarily and directly rely on technical sciences. Informatics, amongst other things, provide us with the software and hardware necessary for the above processes (for example design and testing platforms) and applications ensuring access to the services of the ground control and support, visualization, and communication subsystems necessary for the safe operation of UAVs. Telecommunication gave us the means of radio communication between the UAV and the ground-based subsystem in the form of wave shapes, modulation, encoding, and cyphering processes. Automatization and information technology ensures the control and adjustment functions and solutions enhancing autonomy and the adequate operation of the integrated flight control subsystem (autopilot). Electrotechnics provides the theoretical background of all electronic circuits in the system, while their practical realization and manufacture of electric parts, sensors and batteries necessitate the electronic devices and technologies discipline. Research of air navigation procedures and technical solutions necessary for their safe operation — such as handling UAVs as an aircraft, and integration of UAVs in the same airspace-falls under the transportation and vehicle sciences category. Material science and technology, and fibre- and composite technology have also contributed to the creation of several subsystems. Research of structural material is worth mentioning here, which aims to enhance the resistance, reduce the weight and increase the life-span of all structural elements and moving parts (mechanical and platform subsystem). Efforts to increase the energy density of batteries are to be emphasized, as part of the energy subsystem. The results of machine design, as part of the mechanical subsystem, both affect the shaping of airframes and propulsion units. 


\section{UAS Technology and its Technical Parameters}

Moving on from the scientific aspects to the technical dimension, it is practical to examine the effects of the innovation and development of the drone industry on the technical parameters of individual pieces of equipment. This is the basis of evaluation of the equipment's suitability for the given purpose. For a given system of publicservice tasks, knowing the requirements of the user organizations, a comparison of such parameters will help to establish the type and quantity of the necessary UAVs, and the conditions of a minimum-level, the optimal, or an "oversized" operation (provision of backup equipment, transportation capacity, operators, fuel supply, other necessary support and servicing, etc.), or the fields to be developed and the direction of development.

The technological development of several academic fields witnessed in the last few decades generated revolutionary changes, as a result of which the costs of the initial investment of several modern technical solutions have reduced, allowing for a cost-efficient creation of complex systems. As a result of these processes, in addition to the primarily fixed-wing, bulky, costly UAVs of exclusively military purpose (MQ-1 Predator, [7] RQ-4 Global Hawk, [8] MQ-9 Reaper [9]), civil equipment (mostly government use) has also emerged, giving rise to commercial and recreational uses. At the same time, development has to date been propelled by the market of multirotor, electric engine equipment emerging from RC modelling. This significantly affects fixed-wing constructions and opens up new perspectives in terms of applications, including government uses.

Figure 3 shows a schematic structure of a UAS version. Logically, Unmanned Aircraft Systems can be broken down into two large subsystems, which contain further, distinct functional blocks. The features and operational characteristics of these individually affect the equipment's technical parameters and their limitations. At the same time, it is the quality of their synergy that determines the system's actual capabilities and features that are important for its practical use. However, in terms of reliable and safe operation, the human operator is also part of the system in a wider sense, though often regarded as secondary, along with elements of maintenance technical service (maintenance, repair and provision of backup equipment). These latter two factors are significant, especially for government use, as usually equipment is available through procurement or own development and manufacture, and its technical parameters are known, but efficiency of its operation is determined by the knowledge, skills and experience of the operators and the logistical background responsible for availability.

The development direction of the individual subsystems is basically determined by the technical opportunities and users' needs, along with the associated characteristic market trends. Emphasizing one of the most important technical dimensions, namely nanotechnology, it is worth mentioning that it is the most dynamically growing and miniaturizing segment of material sciences and technology. [10] [11] It contributed to the reduction in size of electric spare parts and sensors, the enhanced complexity of integrated and programmable circuits, and the opportunity to use solid, resistant, yet light structural materials. At the same time, it significantly affects the development of power sources, as using nanostructure materials with targeted design, manufactured under controlled circumstances and built from various atoms, allows for the manufacture of greater energy density and lower specific weight batteries, with more beneficial electric 
features (for example life-cycle, charging time, environment-resistance). [12] Using such materials gives UAS designers more flexibility, for example when optimizing flying time and weight for a given task. For all subsystems, material science and technology are significant and increasingly dominant. Even more so, if during the development process we consider the cycle of creation of prototypes both in terms of time and costs. Due to ongoing revolutionary changes in the field of $3 D$ printing, the methods used for not only the manufacturing of prototypes, but also for the end products, has become increasingly efficient. [13] These opportunities may propel the research of identical structure minidrone swarms, even with a large number of drones. [14]
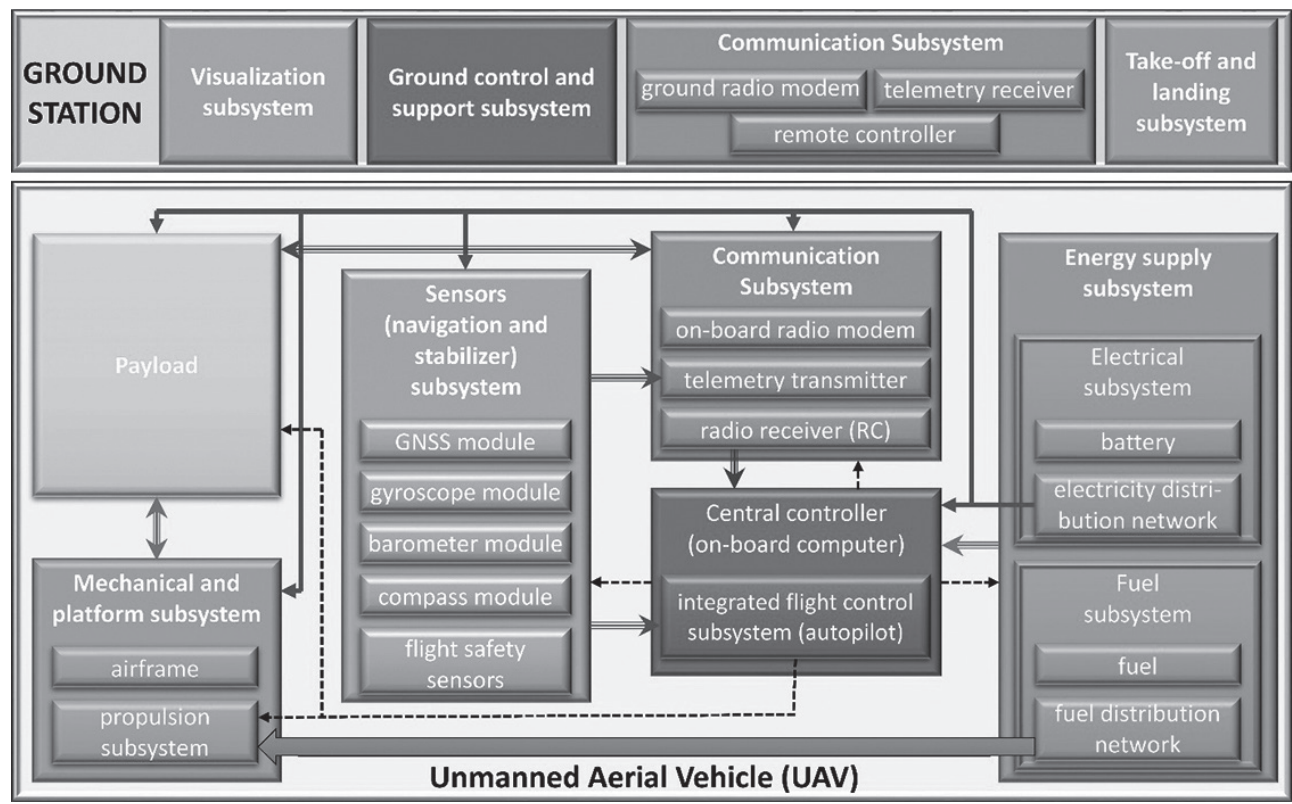

Figure 3. A generalized UAS structure.

[Created by the author.]

However, the practical use of mini-drone swarms requires advances in another area, as well. The use of automation and information technology toolkits is also essential for the ability to create a collective intelligence for the drone swarms. Task sharing at the highest possible level of autonomy is allowed by research results in the field of neural networks, artificial intelligence, and machine learning methods. [15] [16] Additionally, increasing computing and data storage capacities affects the control of UASs, by increasing quantities of real time access, and processing data provided by the increasingly complex sensor system (e.g. multi-direction ultrasound and optical sensors, range indicators, compasses, accelerometers and barometers). [17] On the other hand, information coming from on-board devices and surveillance systems (e.g. ultra-high-resolution cameras, highly sensitive heat cameras, radio frequency surveillance equipment) have to be continuously saved and transmitted to the ground-based subsystem's data processing centre, along with the telemetric data, through a broadband high frequency datalink. [18] 
And adequate technical background for the latter functions, including remote control by a reliable and secure radio frequency, is provided by the continuous development of telecommunication technologies, and the development and integration of new wave forms and modulation, encoding and cyphering methods. The goal is to transmit as much information as possible within a given amount of time, as independent as possible from the electromagnetic environment and weather conditions. For the ground-based subsystem, the most important software factors are data processing, analysis, evaluation and imaging. Efforts are made in the direction of the highest possible automation of processes. As it is about aircraft, establishment of the exact geographical location of the equipment is vital for both the control of the UAV, and for efficient execution of tasks. Detailed fight planning and routing, even considering meteorological conditions, may significantly reduce the time used for reconnaissance of a given area. This facilitates coverage of larger areas with one flight, for example with a given battery capacity. By using Global Navigation Satellite Systems (GNSS) receivers [19] and ground-based or satellite differential supplementary solutions, this will be a reality in the near future, possibly with a centimetre-scale accuracy, facilitating flight planning or linking measurement information to geographical location points and graphic imaging through Geographic Information System (GIS) applications. [20] [21] At the same time, significant progress is needed to efficiently process the increasing volume of information collected by drones, with the least human intervention possible.

Spreading of practical applications is affected by the level of aviation safety, improvement of which requires accurate navigation and significant development of the autopilot and sensor systems. This is essential to minimize risks by increasing autonomy, by using technologies to prevent, detect and avoid emergencies, and by enhancing the security and reliability of datalinks, even under the following circumstances: low-altitude, belowthe-horizon operations (terrain following, obstacle avoidance); flights in busy airspaces (collision avoidance); night flights; flying above people or masses of people; flying among buildings; or a combination of the above. Of course, this would necessitate a change of generations in airspace management, airspace oversight and air traffic control, just like in the broadband mobile communication (5G) services and cloud-based storage services responsible for the transmission of data.

Another large and complex impact area affecting several subsystems is flight time. For example, for a multicopter, increasing the volume of the on-board battery will also increase the available electrical power. But the increased weight will result in increased use of electrical power by the engines, in other words, the additional power will be used up faster. This latter will decrease the effects of the first factor, therefore the flying time will increase in a limited way, but engines will depreciate faster. The goal is to increase the energy density of power sources (e.g. fuel cells [22]) and decrease the total weight of the UAV (use of low specific weight material), reduce the power consumption of the engines, and optimize flight controlling algorithms (reduction of the number and extent of interventions). Primarily, for fixed wing constructions reduction of drag is also an important challenge. Use of solar panels would increase flying time further. 


\section{Classification of Unmanned Aircraft Systems with Special Regards to Public Service Uses}

Unmanned Aircraft Systems can be classified by several criteria, but usually it is done by the physical characteristics or flying parameters of the aerial subsystem, i.e. the UAV, such as maximum take-off weight, range, cruising altitude, or flying time. Based on the above parameters, one of the most accepted classifications was put together by the Unmanned Vehicle Systems International (UVSI) non-profit international association, in which they attempted to blur the line between civil and military use equipment. The tactical level contains 10 subcategories (nano, micro, mini, Close-Range - CR; Short-Range - SR; Medium-Range - MR; Medium-Range Endurance - MRE; Low Altitude Deep Penetration - LADP; Low Altitude Long Endurance - LALE; Medium Altitude Long Endurance MALE), with the upper limit of $1,500 \mathrm{~kg}$, a range of $500 \mathrm{~m}$ or higher, cruising altitude of $14,000 \mathrm{~m}$, and a flying time of 48 hours. Strategic level UASs entail the categories High Altitude Long Endurance (HALE) and Unmanned (or uninhabited) Combat Air Vehicle (UCAV) (12,500 kg, a range of 2,000 km or higher, cruising altitude of 20,000 $\mathrm{m}$ and a flying time of 48 hours), while the group of special purpose equipment features the combat Lethal (LETH) and Decoy (DEC) UAVs. [23] [24] [25] [26] In terms of Hungarian use, the lower five categories of tactical level are potentially relevant for public service uses.

A further potential basis of classification is: structure (fixed wing, rotary wing, hybrid), engine type (piston, gas turbine, electric), method of control (remote control, programmed, combined), method of launching, and landing or purpose. [23] Figure 4 shows a generally accepted classification.

Based on the trends emerging in the last five years, it can be stated that due to the development of flight control systems, the share of multirotor constructions on the market of recreation equipment has drastically grown. This growth is induced by their beneficial features, and mostly their simple operation. The accurate GNSS receivers and modern complex sensor systems ensure unprecedented stability and excellent flying characteristics for such equipment. Automatic collision avoidance, obstacle avoidance, and emergency landing solutions significantly enhance the safety of operations, even for untrained operators. GIS-based flight planning and control systems, broadband radio frequencies (full High Definition [HD] video signals, telemetry, remote control), flexible flight parameters configurable during flight, the limitations and services, all offer an increasingly wide range of uses. With batteries available in commercial circulation, a flying time of more than 30 minutes is achievable, subject to volume, type of payload, method of use (such as increased speed, continuous UHD video capture) and environmental factors (wind). Depending on financial limitations, users are free to choose a 6-, 8-, or even a 12-rotor UAV for a few thousand dollars, which are able to carry a 10-20-30 kg payload, [27] or continue flight and/ or land with one or even more unserviceable rotors. 
A. NÉMETH: Technical Dimensions of the Development of Unmanned Aerial Systems...

UAV Configuration Types

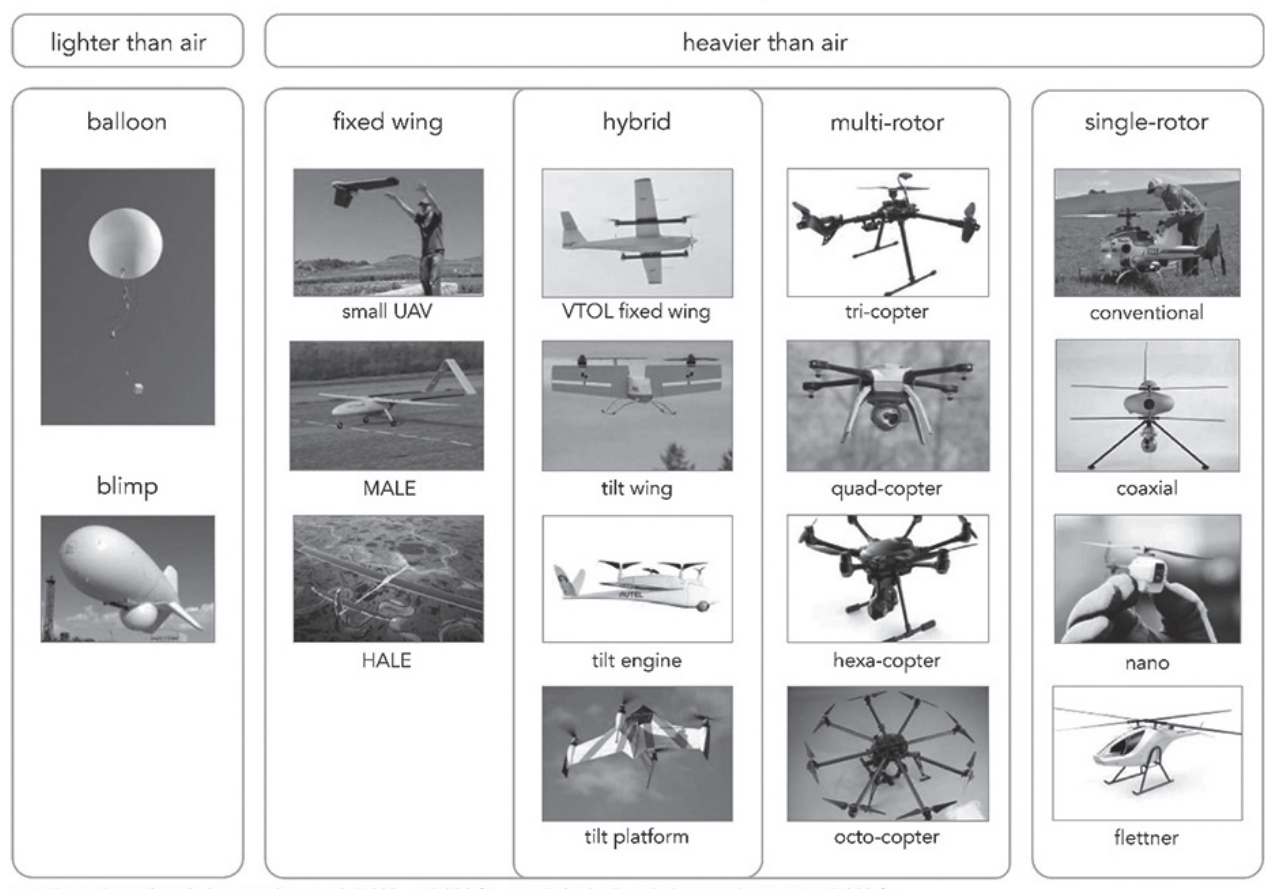

MALE: medium altitude long endurance $(15.000-45.000 \mathrm{ft}$.), HALE: high altitude long endurance $(>45.000 \mathrm{ft}$.)

Figure 4. UAV configuration types. [28]

In this price category, flexibly configurable constructions are available that are optimized for the given task. They can carry ultra-zoom cameras, multispectral reconnaissance equipment, radio relays, decoys, transportation containers, or even battery blocks to extend flying time.

The use of electric multicopters is supported by the fact that take-off and landing is done vertically, and does not require a special launching pad or lengthy preparation, while also being low-maintenance. They reach cruising altitude at an even 5-10 m/s climbing rate, which combined with a low noise level allows for stealth, even from a few hundred meters of altitude and/or distance.

At the same time, fixed solutions exist that allow for an unsupervised and permanent presence at an altitude of 80-100 m, even for hours [29] or days, with only one launch. In addition to the cumbersome and expensive balloon-based solutions, it can provide an option for law-enforcement where the task involves infrared surveillance of longer river or border segments, provision of relay services above an area uncovered by communication services, or monitoring of mass events, festivals, or objects.

Moving on to the possibilities of public functions, the following reasoning proved to be practical: the government tasking system laid down in the applicable Hungarian law and the organizational structure responsible for the execution of such tasks, shall always efficiently respond to the challenges of the era and to arising security threats. The equipment system used to carry out these shall always be based on the services provided by the latest technologies, 
methods and procedures. Based on the above requirements, public service use of drones is obvious, and is in line with international trends. At the same time, considering the forecasted volume of this market and the scale of future uses, handling of this field shall be escalated to a strategic level to provide government players with a customized equipment fleet at all times. Analysing the features of UAS categories, it can be established that except for a few special applications - for example long-range reconnaissance or military cartography, or air defence decoy missions, highway monitoring or firefighting-due to their positive features, it is practical to focus on multicopters. Multicopters are able to rapidly change directions and positions, hover over one spot, or follow moving targets. Thus, they can be put to good use in urban or other complex environments. They are capable of operating without emissions or other harmful effects, and with negligible noise volume, which ensures that such operations remain stealthy. These characteristics are of a universal and great importance. Yet, they are mostly appreciated for their policing, national security, or environmental protection uses.

In the task system of law enforcement, the use of drones could be very practical and efficient. [30] In crime prevention, patrol over endangered areas can reduce the risk of crime, while for crimes already committed, investigation can be supported by drones. At the same time, there are various arguments for the use of drones for crime or accident scene investigations, or other investigations, evidencing procedures, or covert data collection. Further potential areas of use are various police operations, securing venues or events, deployment of troops, preparation of raids, or the border patrol or oversight functions mentioned earlier, and the complex task system of combating illegal immigration and human trafficking. In connection with this, the circle of users is expanded to the staff of the Counter Terrorism Centre, who play an important role in combating terrorism. In the future, the equipment system could be expanded by ultra-small size UAVs for indoor flights for, for example, reconnaissance in closed areas prior to freeing hostages, for diverting attention during the operation itself, for carrying communication devices or other equipment preserving the lives of hostages in the closed area, or for remotely launching smoke grenades. The task system of some units of the National Tax and Customs Administration are similar to these activities, thus similar uses are also within our scope. Important tasks in prisons could be to secure such institutes against escape, prevent transportation of illegal objects into the building, or monitor the working sites outside of the facility. In the future, such tasks could be supported by drones for enhanced efficiency.

Possibilities of using UAS solutions for a wide spectrum of operations open up in the fields of disaster prevention and response, and the associated firefighting, industrial security and civil protection and water-related activities. [31] [32] In addition to reconnaissance, security and search and rescue tasks, UASs can be used for several other special purposes during activities in connection with nuclear or industrial accidents, accidents involving hazardous cargo transport, forest fires, or mass traffic accidents. For example, searching for sources of fire, analysis of fire spread parameters, evaluation of the condition of dams, filtering risk factors, use of firefighting containers, release of neutralizing material, or evaluation of the conditions of infrastructure elements and networks.

As for the support of authority tasks, the potential areas for UAS use would be environment protection and animal and forest management, or uses associated with local government work. In the former case, it is worth mentioning cost-efficient assessment of swamp areas or flooded areas that are otherwise difficult to access, protection of the borders 
of protected areas, for example in the vicinity of cultivated lands via photometric comparison of photos captured during programmed flights. [32] The use of drones has the potential to offer efficient remote control solution for combating a wide range of unlawful activities, such as depositing waste, wastewater handling, campfires or timber mining, hunting, fishing, or other environmentally damaging activities. It can also be used to observe the movement of animal herds, count their population, or observe natural habitats without considerable disturbance of the environment. In urban areas, to verify compliance with the requirements of the construction authority or reconnaissance of illegal constructions, to prepare energyefficiency assessments, even verification of heating systems operating with fossil-based or other fuel in winter (emission-level). Over industrial areas or dangerous facilities, deploying chemical, biological, or optical sensor systems would facilitate verification of compliance with permitted emission-levels, both regularly and randomly. Images captured by drones and the electronic measurement reports can serve as evidence in criminal procedures. In the field of frequency management, drones can prove useful in finding and identifying unauthorized radio frequencies. Multicopters can penetrate dangerous, otherwise inaccessible areas, while carrying special payloads to carry out chemical or physical sampling with low risk.

Though the above list is not complete, it clearly shows the unbelievably wide range of non-military use UASs are offering. In connection with the issue of usability, it should be noted that the emphasis is nowadays shifting from the carrier platform to payloads and the automated processing of real time information they produce, thus governments should also put more emphasis on these factors. Establishment and updating of categories of individual task systems, and the associated technical requirement system, is a more complex task than it appears at first. For Hungarian circumstances, almost all deployed versions have to fit in the weight category comprising UAVs below $150 \mathrm{~kg}$, but with compromises and with the continuous development of such equipment, this weight limitation can even be reduced to $25 \mathrm{~kg}$. One consideration has to be applied by all means, namely that efficient execution of the government's task system is based on the close cooperation between bodies, which also affects the use of UAV systems. Therefore, cooperation during the establishment of categories is paramount.

\section{Summary}

Based on both the military and commercial purpose forecasts, the next decades will bring about a widespread use of unmanned aerial vehicles. In addition to military applications, this growth will be propelled by other government and public service uses, along with the expansion of industrial uses associated with strategic industries (energy).

However, due to the exponential and complex technical development processes (e.g. increased autonomy levels, use of collective group intelligence), costly military developments (and not only in this field) are gradually losing their technological benefits, and demands are growing for the adaptation and integration of cost-efficient civilian technology and equipment.

In order for government players to keep up with these processes, a drastic change of view and concepts is necessary, allowing significantly greater flexibility and cooperation between stakeholders. The long-term solution should be presented by a system of associations, 
which is based on a broad scale cooperation bringing strategic level users, industrial and other market players, authority bodies and university research workshops, on a mutual and unified national platform. This "Unmanned Aircraft Systems Information, Support, Knowledge and Education Center” would mean not only a formal cooperation, but would present us with a strategic, planning, decision-preparation and development organization that handles associated legal and technical issues as a complex problem, considering the needs of government users (defence, law enforcement, disaster response). A “testbed”, an experimental platform, would be created under the auspices of the Center, allowing industrial stakeholders to promptly examine their latest developments, free of significant administrative burdens. It would also facilitate integration of individual subsystems and continuous testing of equipment. The same platform would give room to carry out experiments necessary for the authorization processes associated with authority activities. The centre's workshops would also establish the guidelines and priorities of the "National Drone Strategy", laying down the basic framework for future developments.

To support developments, an extensive central database and the associated multi-level decision preparation system would be set up, which includes all complete UASs available on the market, with their technical parameters, flying characteristics, and ownership and supplier backgrounds. Additionally, it would feature the latest information about international developments, available modules for each subsystem (autopilot, batteries, engines, sensors, communication systems, airframes, etc.), with all physical parameters, characteristics, limitations, and other supplementary data. When entering filter conditions in a special search engine, it will offer solution alternatives for the individual components or the complex system, just like an online catalogue, assessing relevance.

This solution would support customers in laying down the realistic requirements towards the UAS to be used for the given purpose, while developers would be able to choose the most efficient technical solution.

This same organization would also lay down the technical requirements and realize an experimental system of a high autonomy traffic management and traffic control, facilitating the safe management of, for example, an urban drone airspace. The principle would be based on radio communication between UASs, transmitting their identifiers and telemetric data to the system's regional processing center, following each equipment and estimating their trajectories. To avoid emergencies (running out of battery power, malfunctions, or collisions), the system would be able to intervene in the control of individual equipment (e.g. avoidance manoeuvers, stop and hover, land), considering their priority levels (for example government, commercial, recreational use), their type (fixed wing or rotary wing), and their flying characteristics. Such solutions would of course require a substantial infrastructure (radio stations, emergency landing strips, meteorological stations), a standardized UAS equipment fleet, and communication protocols. But in the light of current development trends, this might be necessary within a few decades, provided we intend to exploit the opportunities UASs offer. 
A. NÉMETH: Technical Dimensions of the Development of Unmanned Aerial Systems...

\section{References}

[1] The Drones Report: Market forecasts, regulatory barriers, top vendors, and leading commercial applications. Business Insider Intelligence, 10.06.2016. www.businessinsider.com/ uav-or-commercial-drone-market-forecast-2015-2 (Downloaded: 10.10.2017)

[2] TOSCANO, M.: Global Aerial Drone Market. Teal Group, BI Intelligence Estimates. s.d. https://static.businessinsider.com/image/54ad8f0269bedd7078ba7175/image.jpg (Download-ed: 02.03.2018)

[3] Unmanned Aerial Vehicle (UAV) Market by Application, Class, System (UAV Platforms, UAV Payloads, UAV GCS, UAV Data Links, UAV Launch and Recovery Systems), UAV Type, Mode of Operation, Range, Point of Sale, MTOW, and Region - Global Forecast to 2025. Research and Markets, February 2018. www.researchandmarkets.com/publication/ mquzwge/4464352 (Downloaded: 06.06.2018)

[4] Unmanned Aircraft Systems (UAS). International Civil Aviation Organization, AN/190 (2011). www.icao.int/Meetings/UAS/Documents/Circular\%20328_en.pdf (Downloaded: 31.12.2018)

[5] Drone, UAV, UAS, RPA or RPAS... AltiGator (online), s.d. http://altigator.com/drone-uavuas-rpa-or-rpas/ (Downloaded: 31.12.2018)

[6] Tudományági nómenklatúra. Budapest: Magyar Tudományos Akadémia, Doktori Tanács, 2017. http://mta.hu/doktori-tanacs/tudomanyagi-nomenklatura-106809 (Downloaded: 07.06.2018)

[7] Aircraft Platforms. www.ga-asi.com/aircraft-platforms (Downloaded: 07.05.2018)

[8] RQ-4 Global Hawk. www.military.com/equipment/rq-4-global-hawk (Downloaded: 07.05.2018)

[9] Predator RQ-1 / MQ-1 / MQ-9 Reaper UAV. www.airforce-technology.com/projects/ predator-uav/ (Downloaded: 07.05.2018)

[10] IONESCU, A. M.: Nanotechnology and Global Security. Connections, 152 (2016), 31-47. www.jstor.org/stable/26326438 (Downloaded: 03.04.2018) DOI: https://doi.org/10.11610/ Connections.15.2.03

[11] TIWARI, A.: Military nanotechnology. International Journal of Engineering Science \& Advanced Technology (IJESAT), 24 (2012), 825-830. http://ijesat.org/Volumes/2012_ Vol_02_Iss_04/IJESAT_2012_02_04_09.pdf (Downloaded: 03.11.2017)

[12] JUN, L., ZONGHAI, C., ZIFENG, M., FENG, P., CURTISS, L. A., AMINE, K.: The role of nanotechnology in the development of battery materials for electric vehicles. Nature Nanotechnology, 11 (2016), 1031-1038. DOI: https://doi.org/10.1038/nnano.2016.207

[13] CHEE, L. C., KAH, F. L.: 3D printing and additive manufacturing: principles and applications (Fifth Edition of Rapid Prototyping). Nanyang Technological University, (2017), 272-278.

[14] KOSLOW, T.: Pentagon to Deploy 3D Printed Mini-Drone Swarms for Surveillance and Attacks. 3Dprint.com, (2016). https://3dprint.com/153572/pentagon-mini-drone-swarm/ (Downloaded: 07.05.2018)

[15] PARPINELLI, R. S., LOPES, H. S.: New inspirations in swarm intelligence: a survey. International Journal of Bio-Inspired Computation, 31 (2011), 1-16. DOI: https:// doi.org/10.1504/IJBIC.2011.038700

[16] BÜRKLE, A., SEGOR, F., KOLLMANN, M.: Towards Autonomous Micro UAV Swarms. Journal of Intelligent \& Robotic Systems, 11 1-4 (2011), 339-353. DOI: https:// doi.org/10.1007/s10846-010-9492-x 
A. NÉMETH: Technical Dimensions of the Development of Unmanned Aerial Systems...

[17] FASANO, G., ACCARDO, D., MOCCIA, A., CARBONE, C., CINIGLIO, U., CORRARO, F., LUONGO, S.: Multi-Sensor-Based Fully Autonomous Non-Cooperative Collision Avoidance System for Unmanned Air Vehicles. Journal of Aerospace Computing, Information, and Communication, 510 (2008), 338-360. DOI: https://doi.org/10.2514/1.35145

[18] MIKÓ, GY., NÉMETH, A.: SCFDM based communication system for UAV applications. In. "Radioelektronika". 25 ${ }^{\text {th }}$ International Conference, (2015), 222-224.

[19] SABATINI, R., MOORE, T., HILL, C., RAMASAMY, S.: Assessing avionics-based GNSS integrity augmentation performance in UAS mission- and safety-critical tasks. In. International Conference on Unmanned Aircraft Systems (ICUAS), 9-12 June 2015. 157-166. DOI: https://doi.org/10.1109/ICUAS.2015.7152347

[20] MANGIAMELI, M., MUSCATO, G., MUSSUMECCI, G., MILAZZO, C.: A GIS application for UAV flight planning. IFAC Proceedings Volumes, 4630 (2013), 147-151. DOI: https://doi.org/10.3182/20131120-3-FR-4045.00025

[21] GEOSYSTEM GmbH: Processing, cataloguing and distribution of UAS images in near real time. International Archives of the Photogrammetry, Remote Sensing and Spatial Information Sciences, XL-1/W2 (2013), 339-342. DOI: https://doi.org/10.5194/isprsarchives-XL-1W2-339-2013

[22] VERSTRATETE, D., LEHMKUEHLER, K., GONG, A., HARVEY, J. R., BRIAN, G., PALMER, J. R.: Characterisation of a hybrid, fuel-cell-based propulsion system for small unmanned aircraft. Journal of Power Sources, 250 (2014), 204-211. DOI: https:// doi.org/10.1016/j.jpowsour.2013.11.017

[23] BÉKÉSI B.: Pilóta nélküli légijármúvek jellemzése, osztályozásuk. In. PALIK M. (szerk.): Pilóta nélküli repülés profiknak és amatőröknek. 2. jav. kiad. Budapest: Nemzeti Közszolgálati Egyetem, 2013. 65-109.

[24] U.S. Army Unmanned Aircraft Systems Roadmap 2010-2035. www.rucker.army.mil/usaace/ uas/US\%20Army\%20UAS\%20RoadMap\%202010\%202035.pdf (Downloaded: 10.11.2017)

[25] CROUCH, C. C.: Integration of mini-UAV at the tactical operations level: implications of operations, implementation, and information sharing. Monterey: Naval Postgraduate School, 2005. www.e-education.psu.edu/geog892/sites/www.e-education.psu.edu.geog892/files/ Collier_Crouch_thesis_a435680.pdf (Downloaded: 15.02.2018)

[26] WATTS, A. C., AMBROSIA, V. G., HINKLEY, E. A.: Unmanned Aircraft Systems in Remote Sensing and Scientific Research: Classification and Considerations of Use. Remote Sensing, 4 (2012), 1671-1692. DOI: https://doi.org/10.3390/rs4061671

[27] Top 10 Heavy Lift Drones. https://filmora.wondershare.com/drones/top-heavy-lift-drones. html 2018 (Downloaded: 10.06.2018)

[28] UAV Configuration Types. Drone Industry Insights, 2016. www.droneii.com/wp-content/ uploads/2016/06/UAV-platform-configurations-compr.png (Downloaded: 10.09.2017)

[29] Vezetékes táplálású drón. Rotors \& Cams, s.d. https://rotorsandcams.com/drotosdron/ (Downloaded: 05.06.2018)

[30] PETRÉTEI D.: A drónok krimináltechnikai és rendészeti felhasználása. Magyar Bûnüldöző, VI 1-3 (2015), 70-81.

[31] BODNÁR, L., RESTÁS, Á., QIANG, X.: Conceptual Approach of Measuring the Professional and Economic Effectiveness of Drone Applications Supporting Forest Fire Management. Procedia Engineering, 211 (2018), 8-17. DOI: https://doi.org/10.1016/ j.proeng.2017.12.132

[32] RESTÁS Á.: Az UAV közszolgálati alkalmazásai. In. PALIK M. (szerk.): Pilóta nélküli repülés profiknak és amatőröknek. 2. jav. kiad. Budapest: Nemzeti Közszolgálati Egyetem, 241-280. 